\title{
BUTIA QUARAIMANA (ARECACEAE), UMA NOVA ESPÉCIE PARA O RIO GRANDE DO SUL (BRASIL) ${ }^{1}$
}

\author{
LEONARDO PAZ DEBLE² JOSÉ NEWTON CARDOSO MARCHIORI ${ }^{3}$ \\ FABIANO DA SILVA ALVES ${ }^{4}$ ANABELA SILVEIRA DE OLIVEIRA DEBLE 5
}

\section{RESUMO}

Uma nova espécie de Butia (Becc.) Becc. é descrita e ilustrada para o Rio Grande do Sul. Comentários sobre a distribuição geográfica, conservação e afinidades são fornecidos.

Palavras-chave: Butia quaraimana, Butia yatay, Palmar do Coatepe, Rio Grande do Sul, Taxonomia Vegetal.

\section{ABSTRACT}

[Butia quaraimana (Arecaceae), a new species from Rio Grande do Sul state, Brazil].

A new species, named Butia quaraimana Deble \& Marchiori is described and illustrated from Rio Grande do Sul state, Brazil. The new species is endemic of the "Palmar do Coatepe", east of Quarai city, where it grows on sandstone soils. Butia quaraimana, by bigger size of pistillate flowers, beaked fruits and shape of endocarp belongs to group of Butia yatay (Mart.) Becc. The new species differs of B. yatay by shorter trunk $(2.5-6.5 \mathrm{~m}$ vs. 6-14 m), 12-16 contemporary leaves (vs. 16-24), middle pinnae with $45-65 \mathrm{~cm} \times 1.2-2 \mathrm{~cm}$ ( vs. $55-80 \mathrm{~cm}$ x 2-3 cm wide), and elliptic shape of endocarp (vs. ovate-elliptic), measuring 18-22 mm x 10-12 mm (vs. 24$28 \mathrm{~mm} \times 14-18 \mathrm{~mm}$ ). Butia quaraimana is also related with $B$. witeckii $\mathrm{K}$. Soares \& Longhi, from wich it differs by number of inflorescence rachillae (108-152 vs. 66-85), smaller pistillate flowers (11-13 mm vs. 14$20 \mathrm{~mm}$ ), size of fruits $(3.5-4.5 \mathrm{~cm} \times 2-2.8 \mathrm{~cm} v s .3 .6-5.6 \mathrm{~cm} \times 3-4.1 \mathrm{~cm})$, and not angulated endocarp (vs. angulated), measuring 18-22 mm x 10-12 mm (vs. 28-35 mm x 16-23 mm). From Butia missionera Deble \& Marchiori, the new species differs by erect-patent or revolute old leaves, not covering the trunk (vs. downrevolute old leaves, covering the distal half of the trunk), almost cylindrical trunk (vs. thickened at the base), with $30-40 \mathrm{~cm}$ wide $(v s .50-60 \mathrm{~cm}), 12-16$ contemporary leaves $(v s .25-40)$, and ovate turbinate fruits ( $v s$. broadly ovate).

Key words: Butia quaraimana, Butia yatay, Palmar do Coatepe, Rio Grande do Sul state, Plant Taxonomy.

\section{INTRODUÇÃO}

O mais antigo registro científico sobre a ocorrência natural de butiás no município de Quaraí (Rio Grande do Sul) se deve a Marchiori et al. (1995), autores que identificaram Butia yatay (Mart.) Becc. como espécie formadora do "Palmar do Coatepe". Diversas publicações sobre a mesma vegetação, vindas a lume na se-

1 Recebido para publicação em 10-11-2011 e aceito para publicação em 15-12-2011.

2 Dr. Professor dos cursos de Ciências Biológicas e Farmácia, URCAMP (Bagé, RS). deble.biol.@gmail.com

3 Dr. Professor do curso de Engenharia Florestal, UFSM (Santa Maria, RS).

4 Msc. Professor do curso de Ciências Biológicas, URCAMP (Alegrete, RS).

5 Dra. Professora do curso de Tecnólogo em Gestão Ambiental, URCAMP (Dom Pedrito, RS). quiência, apontam para esta Arecaceae, casos de Marchiori \& Alves (2011A, B) e Deble et al. (2011), entre outras. Soares \& Witeck Neto (2009), por outro lado, referem-se à palmeira do Coatepe como sendo Butia paraguayensis (Barb. Rodr.) L.H. Bailey. Do acima exposto, vê-se que não existe consenso sobre a identidade botânica desta espécie de palmeira, motivo que justifica a realização do presente trabalho.

Mesmo sem qualquer menção ao palmar em foco, Sobral et al. (2006) atribuem ocorrência esporádica a Butia yatay no Rio Grande do Sul, restringindo a espécie à região das Missões. Cabe notar que esta distribuição geográfica coincide com o descrito por Reitz et al. (1983), que mencionaram "densos aglomerados" desta palmeira na mesma região, ditos "butiatubas". Com maior precisão, Mattos (1977) indica a 
ocorrência natural de Butia yatay no município de Giruá, noroeste do Rio Grande do Sul ${ }^{6}$.

Em obra abrangente sobre as Arecaceae no Brasil, Lorenzi et al. (2010) assinalam a presença de "densas colônias" de Butia yatay em solos arenosos da "região fronteiriça" do Rio Grande do Sul com a Argentina e o Uruguai. Cabe notar que as duas coletas indicadas pelos autores são procedentes do município de Quaraî?.

O presente trabalho tem o objetivo de elucidar a identidade botânica da espécie de butiá que se encontra no Palmar do Coatepe, município de Quaraí, Rio Grande do Sul. Para tanto, convém examinar-se, de início, a literatura concernente à descrição original de Butia yatay (Mart.) Becc., espécie formadora de extensos palmares na Mesopotâmia argentina, notadamente nas províncias de Corrientes e Entre Rios.

\section{APONTAMENTOS BIBLIOGRÁFICOS}

Descrito por Martius (1844), sem a indicação do correspondente Typus ${ }^{8}$, Cocos yatay Mart. foi transferido ao gênero Butia por Beccari (1916). O primeiro destes autores remete a identidade da espécie ao texto seminal de Alcide Dessalines D'Orbigny, constante em sua monumental Voyage dans l'Amérique Méridionale, obra composta de nove volumes e mais de cinco mil páginas, editada por Pitois-Levrault entre 1835 e 1847.

Devido à citação expressa de Martius, o exame do texto de D'Orbigny, juntamente com a descrição botânica e correspondente iconografia, se mostram indispensáveis ao reconhecimento, na natureza, da população original de

${ }^{6}$ Os palmares de Giruá pertencem, em verdade, a espécie recentemente descrita: Butia missionera Deble \& Marchiori (Deble et al., 2011. Op. cit., p. 10-15).

7 R. Tsuji 1741, Quaraí, RS (HPL); V. Kinupp et al. 2961, Quaraí, RS (ICN).

8 Para Cocos yatay, Martius (1844:94) refere: "Crescit in provincia Corrientes et in regione, quam Indi Guarani incolunt, his Yatayi (...) Cette espèce forme des forets immenses sur tous les terrains sablonneux des provinces de Corrientes et d'Entre-Rios (republique Argentine)". yatais a que se refere o viajante-naturalista francês.

Obra rara, encontrada apenas em poucas bibliotecas, a "Viagem pela América Meridional" dispõe, felizmente, de uma edição recente ${ }^{9}$ do texto relativo à Argentina, traduzido ao espanhol por Alfredo Cepeda, em 1945.

Vindo da França, Alcide D’Orbigny chegou a Montevidéu em 2 de dezembro de 1826 e, após viagem por terra à Colônia do Sacramento, alcançou Buenos Aires em fins de janeiro de 1827, seguindo em viagem pelo rio Paraná a 14 de fevereiro do mesmo ano, rumo à cidade de Corrientes.

Os primeiros yatais referidos por D'Orbigny foram encontrados a 24 de abril de $1827 \mathrm{em}$ Yataity, lugarejo situado a nordeste da capital (ciudad de Corrientes):

"Crucé por tierras parecidas a las de Las Ensenadas, elevaciones arenosas, cortadas por lindas lagunas y separados grupos de árboles. Allá vi, por primera vez, la palmera que los indígenas dieron el nombre de yatai, lo que hizo que se llamara a esta localidade Yataity, que em guaraní significa bosque de yatais o lugar cubierto de yatais (...). Esta palmera crece poco. Su tronco es grueso y cubierto de antiguas marcas correspondientes a la insersión de las hojas, en las que arraigan con facilidad unos fícus que terminan por sofocar el árbol. Las hojas de esta palmera son elegantemente arqueadas y el verde azulino de sus foliolas que apuntan al cielo contrasta agradablemente con la vegetación de los alrededores". ${ }^{10}$

Ao tempo da viagem de D'Orbigny, o palmar de Yataity já estava praticamente destruído, tanto pela necessidade de "preparar el terreno para la agricultura", como pelo "interés por el sabroso alimento que contituye su corazón", ou seja, pela extração do palmito ${ }^{11}$. Palmares extensos e pra-

9 Referimo-nos, aqui, à edição de 1998, posto que a obra em espanhol mereceu edição anterior.

${ }^{10}$ D'ORBIGNY, A.D. Viaje por América Meridional. Buenos Aires: Emecé, 1998. v, 1. p. 148.

${ }^{11}$ D'ORBIGNY, 1998. Op. cit., p. 148. 


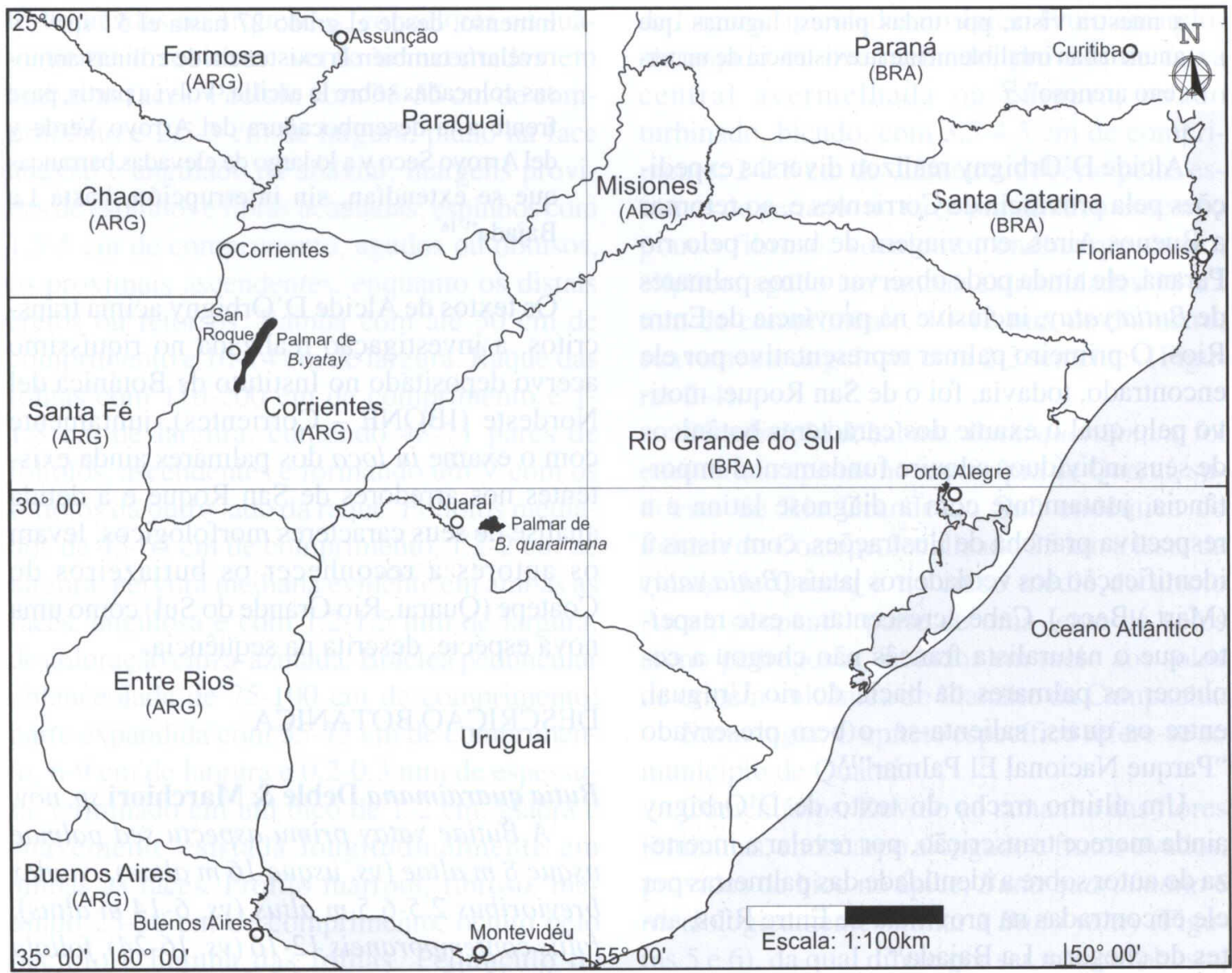

FIGURA 1 - Mapa de localização dos palmares de Butia yatay (São Roque, Corrientes, Argentina) e Butia quaraimana (Quaraí, Rio Grande do Sul, Brasil).

ticamente intocados de Butia yatay somente foram encontrados pelo naturalista francês nos arredores de San Roque, localidade ao sul da cidade de Corrientes (Figura 1). A 28 de junho, ao sair de San Roque em direção ao "Rincón de Luna", o viajante cruzou, inicialmente, por um campo descoberto, sem árvores, registrando, na seqüência:

"Una lejana masa azulada, de aspecto nuevo para mí, se desplegaba ante nosotros, presentándonos inmensos bosques de palmeras yatay. A medida que nos aproximábamos, distinguíamos primero las plantas separadas, luego las pequeñas copas que cubrían un tronco delgado; por fin llegamos a las primeras. Sólo las había visto bajas y achaparradas, en Yataití, camino a Iribicuá. Allí las encontré grandes, llenas de vigor, sin que hubieran sido nunca atormentadas por el hombre. Estaba encantado con este nuevo género de vegetación. Por todas partes había palmeras cuyas copas redondeadas, de un verde azulino, se componen de largas hojas más o menos curvadas en forma de surtidor, donde las viejas inserciones de las hojas caídas dibujan relieves naturales, en líneas tortuosas. A medida que avanzábamos, el bosque se espesaba y ningún otro árbol aparecía mezclado a las palmeras, que siempre observaba con el mismo gusto. El aspecto de un objeto bello, al que no esté acostumbrada nuestra vista, nos produce una sensación difícil de expressar, pero que no deja de ser real; pronto se le agrega la admiración y un respeto más profundo por la naturaleza toda se hace sentir involuntariamente. En medio de esas brillantes palmeras se ofrecían 
a nuestra vista, por todas partes, lagunas que anunciaban infaliblemente la existencia de un terreno arenoso". ${ }^{12}$

Alcide D’Orbigny realizou diversas expedições pela província de Corrientes e, ao retornar a Buenos Aires, em viagem de barco pelo rio Paraná, ele ainda pode observar outros palmares de Butia yatay, inclusive na província de Entre Rios. O primeiro palmar representativo por ele encontrado, todavia, foi o de San Roque, motivo pelo qual o exame dos caracteres botânicos de seus indivíduos adquire fundamental importância, juntamente com a diagnose latina e a respectiva prancha de ilustrações, com vistas à identificação dos verdadeiros jataís (Butia yatay (Mart.) Becc.). Cabe acrescentar, a este respeito, que o naturalista francês não chegou a conhecer os palmares da bacia do rio Uruguai, entre os quais, salienta-se, o bem preservado "Parque Nacional El Palmar"13.

Um último trecho do texto de D’Orbigny ainda merece transcrição, por revelar a incerteza do autor sobre a identidade das palmeiras por ele encontradas na província de Entre Ríos, antes de chegar a La Bajada ${ }^{14}$ :

"Desde el lugar donde me hallaba, el campo parecía ondularse en algunos sitios y se veía, en el horizonte, un gran bosque de palmeras, cuyo color glauco me hizo suponer que eran yatais; por lo menos formaban como éstos un bosque de poca altura. Si fueran realmente yatais, lo que no puedo asegurar, no habiendo podido reconocerlos, esta especie ocuparía un espacio

12 D'ORBIGNY, 1998. Op. cit., p. 171.

${ }^{13}$ Criado em 1966, o Parque Nacional "El Palmar" tem extensão de 8.500 hectares e visa a proteger um setor muito singular da Mesopotâmia argentina, no que diz respeito à flora e à fauna. Situado no centro-leste da província de Entre Rios, a área do parque era anteriormente conhecida como "Palmar Grande" (ERIZE et al. 1993. Op. cit., p. 90-92).

${ }^{14}$ Nome antigo da atual cidade de Paraná, capital da província de Entre Rios, situada à margem esquerda do rio Paraná.

${ }^{15}$ Erro tipográfico ou evidente exagero, senão equívoco de D'Orbigny (nota dos autores). inmenso, desde el grado 27 hasta el 51 sur $^{15}$, y revelaría también la existencia de colinas arenosas colocadas sobre la arcilla. Volví a partir, pasé frente a la desembocadura del Arroyo Verde y del Arroyo Seco y a lo largo de elevadas barrancas que se extendían, sin interrupción, hasta $\mathrm{La}$ Bajada". ${ }^{16}$

Os textos de Alcide D'Orbigny acima transcritos, a investigação realizada no riquíssimo acervo depositado no Instituto de Botánica del Nordeste (IBONE - Corrientes), juntamente com o exame in loco dos palmares ainda existentes nos arredores de San Roque e a detida análise de seus caracteres morfológicos, levam os autores a reconhecer os butiazeiros do Coatepe (Quaraí, Rio Grande do Sul) como uma nova espécie, descrita na seqüência.

\section{DESCRIÇÃO BOTÂNICA}

Butia quaraimana Deble \& Marchiori sp. nov.

A Butiae yatay primu aspectu sed palmae usque $8 m$ altae (vs. usque $16 m$ altae), caudex brevioribus 2.5-6.5 $m$ altus (vs. 6-14 $m$ altus), foliis contemporaneis 12-16 (vs. 16-24), foliola media 45-65 cm longa, 1.2-2 cm lata (vs. 55-80 $\mathrm{cm}$ longa, $2-3 \mathrm{~cm}$ lata), endocarpio elliptico, 18-22 mm longo, 10-12 mm lato (vs. ovatoelliptico 24-28 mm longo, $14-18 \mathrm{~mm}$ lato), productus bene differt.

TYPUS: BRAZIL. Rio Grande do Sul, Quaraí, Palmar do Coatepe, no campo e encosta, entre rochas, estipe 4-5 m, bráctea peduncular glabra, frutos apiculados, alaranjados, com faixa avermelha central, 15-II-2011, L. P. Deble, A. S. Oliveira-Deble, J. N. C. Marchiori 13988 (Holotypus SI!).

Palmeira solitária com 4-8 $\mathrm{m}$ de altura. Estipe de 2.5-6.5 $\mathrm{m}$ de altura e $30-40 \mathrm{~cm}$ de diâmetro, com remanescentes das bainhas foliares na parte distal e cicatrizes dispostas em torno do estipe na parte proximal. Folhas contemporâneas 1216 , medindo $150-250 \mathrm{~cm}$ de comprimento, ere-

${ }^{16}$ D’ORBIGNY, 1998. Op. cit., p. 465. 
to-arqueadas ou arqueadas, concolores ou suavemente discolores, verde acinzentadas em ambas as faces. Pecíolo com 35-55 cm de comprimento e $2.5-3 \mathrm{~cm}$ de largura, plano na face adaxial e angulado na abaxial; margens providas de espinhos e fibras achatadas; espinhos com $1.5-5 \mathrm{~cm}$ de comprimento, agudos ou obtusos, os proximais ascendentes, enquanto os distais eretos ou retorsos. Bainha com até $50 \mathrm{~cm}$ de comprimento e 10-14 cm de largura. Raque das folhas com 110-200 cm de comprimento e 1$1.8 \mathrm{~cm}$ de largura, contendo $48-71$ pares de folíolos, ascendentes e formando um $\mathrm{V}$ com os folíolos da outro lado da raque. Folíolos medianos de 45-65 cm de comprimento, $1.2-2 \mathrm{~cm}$ de largura, nervura mediana evidente em ambas as faces, angulosa e com 1.2-1.5 mm de largura, de coloração cinza-azulada. Bráctea peduncular oblanceolada de $75-100 \mathrm{~cm}$ de comprimento; parte expandida com $55-75 \mathrm{~cm}$ de comprimento, $6-9 \mathrm{~cm}$ de largura e $0.2-0.3 \mathrm{~mm}$ de espessura, terminado em um bico de 1-2 cm, glabra e suavemente estriada longitudinalmente em ambas as faces. Prófilo marrom, fibroso, medindo $25-30 \mathrm{~cm}$ de comprimento, oculto pelo pecíolo e bainha das folhas. Pedúnculo da inflorescência branco-creme, delicadamente estriado, suavemente anguloso ou terete, medindo $30-45 \mathrm{~cm}$ de comprimento por $1.5-2.2 \mathrm{~cm}$ de diâmetro. Raque da inflorescência branco-creme, angulosa, 40-55 cm de comprimento, com 108-152 raquilas. Raquilas flexuosas, brancocreme ou creme-esverdeadas, as basais com 20$41 \mathrm{~cm}$ de comprimento; as medianas com 13$19 \mathrm{~cm}$ de comprimento, e as apicais com 8-13 $\mathrm{cm}$ de comprimento. Flores estaminadas branco-cremes ou avermelhadas na face ventral; as basais pedunculadas, pedúnculos de $3-5 \mathrm{~mm}$; as superiores sésseis ou quase sésseis; sépalas lanceoladas ou oblongas, 1.8-3 mm de comprimento, 0.8-1.2 $\mathrm{mm}$ de largura; pétalas lanceoladas ou oblongas, 6-8 mm de comprimento, 1.8-3 mm de largura. Flores pistiladas branco-cremes ou creme esverdeadas, ovadoturbinadas, $11-13 \mathrm{~mm}$ de comprimento, 6-8 mm de largura, apiculadas no ápice. Fruto amareloalaranjado ou avermelhado, provido de faixa central avermelhada ou púrpura, ovado turbinado, bicudo, com 3.5-4.5 cm de comprimento, 2-2.8 cm de diâmetro, coberto pelas escamas do perianto no terço proximal; mesocarpo pouco fibroso, suculento; endocarpo ósseo, elíptico, agudo em ambas extremidades 18-22 $\mathrm{mm}$ de comprimento, $10-12 \mathrm{~mm}$ de diâmetro, suavemente anguloso, com 2-3 sementes (Figuras 2-4).

Distribuição \& habitat: Butia quaraimana foi encontrado apenas no município de Quaraí, sudoeste do Rio Grande do Sul, endêmica do Palmar do Coatepe, localizado $25 \mathrm{~km}$ a leste da cidade de Quaraí e no curso médio do arroio Areal, ocupando parte de uma lente de solos areno-pedregosos, isolados em meio aos solos de origem vulcânica do Planalto da Campanha.

Etimologia: O epíteto específico refere-se ao município de Quaraí.

Comentários: Devido ao tamanho das flores femininas, endocarpo alongado e frutos ovados, providos de bico no ápice, Butia quaraimana é morfologicamente similar a Butia yatay (Figuras 5 e 6), da qual difere por ser menos robusta, com os maiores indivíduos medindo até $8 \mathrm{~m}$ de altura ( $v s$. até $16 \mathrm{~m}$ de altura), pelo estipe curto (2.5-6.5 m vs. 6-14 m), pelo menor número de folhas contemporâneas (12-16 vs. 16-24), pelo menor tamanho dos folíolos na parte mediana (45-65 cm x 1.2-2 cm vs. $55-80 \mathrm{~cm} \times 2-3 \mathrm{~cm}$ ), e pela forma elíptica do endocarpo ( $v s$. ovadoelíptica), que mede 18-22 mm x 10-12 mm (vs. 24-28 mm x 14-18 mm). Pelo tamanho do estipe, forma da copa e dimensões das folhas, Butia quaraimana relaciona-se com $B$. witeckii $\mathrm{K}$. Soares \& Longhi, da qual se separa pelo maior número de raquilas na inflorescência (108-152 vs. 66-85), pelo menor tamanho das flores pistiladas (11-13 $\mathrm{mm}$ vs. $14-20 \mathrm{~mm})$, pelo menor tamanho dos frutos $(3.5-4.5 \mathrm{~cm}$ x $2-2.8 \mathrm{~cm}$ vs. $3.6-5.6 \mathrm{~cm} \times 3-4.1 \mathrm{~cm}$ ), assim como pelo endocarpo desprovido de quinas ( $v s$. provido de quinas longitudinais), medindo $18-22 \mathrm{~mm} \times 10$ - 


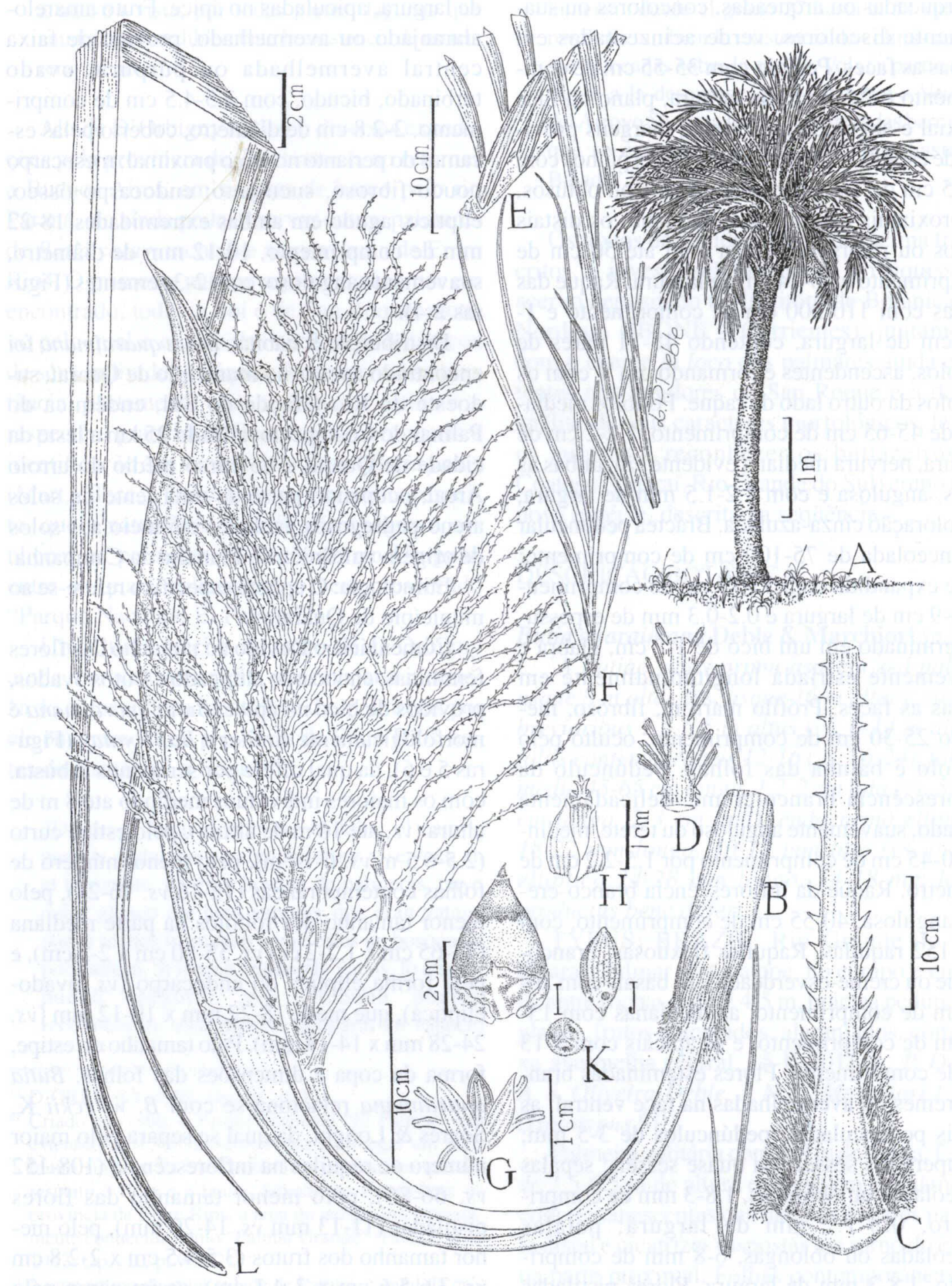

FIGURA 2 - Butia quaraimana. A - Hábito. B - Inflorescência. C - Pseudopecíolo. D - Porção basal da folha. E - Porção mediana da folha. F - Porção apical da folha. G - Flor estaminada. H - Flor pistilada. I - Fruto maduro e perianto. J - Endocarpo. K - Endocarpo, visão dos poros. L - Folíolo da parte mediana da folha ( A-J de L. P. Deble, A. S. de Oliveira-Deble \& J. N. C. Marchiori 13998). 


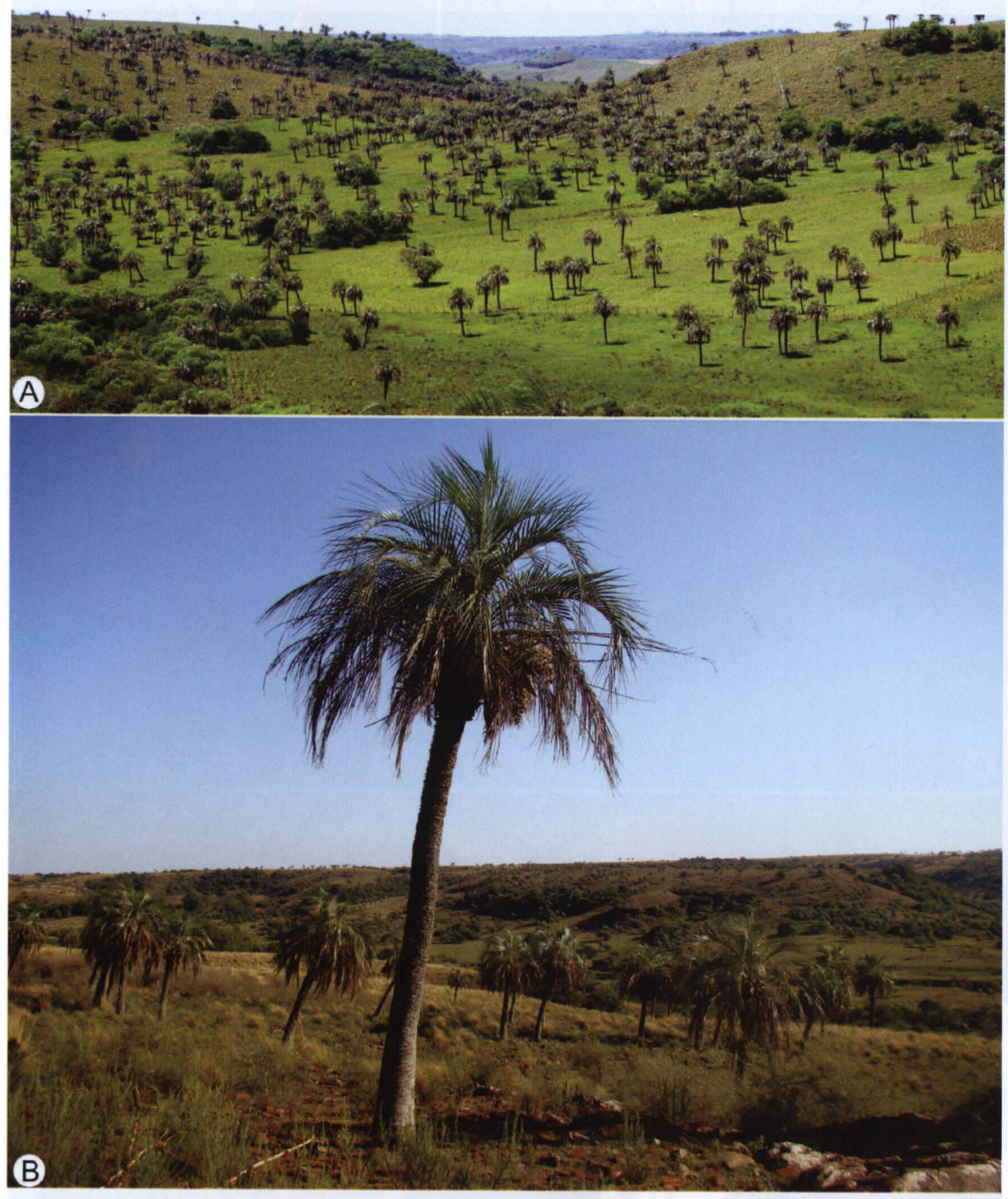

FIGURA 3 - Dois aspectos do Palmar do Coatepe. A - Vista panorâmica. B - Indivíduo de Butia quaraimana com cerca de $6 \mathrm{~m}$ de altura, em primeiro plano. 


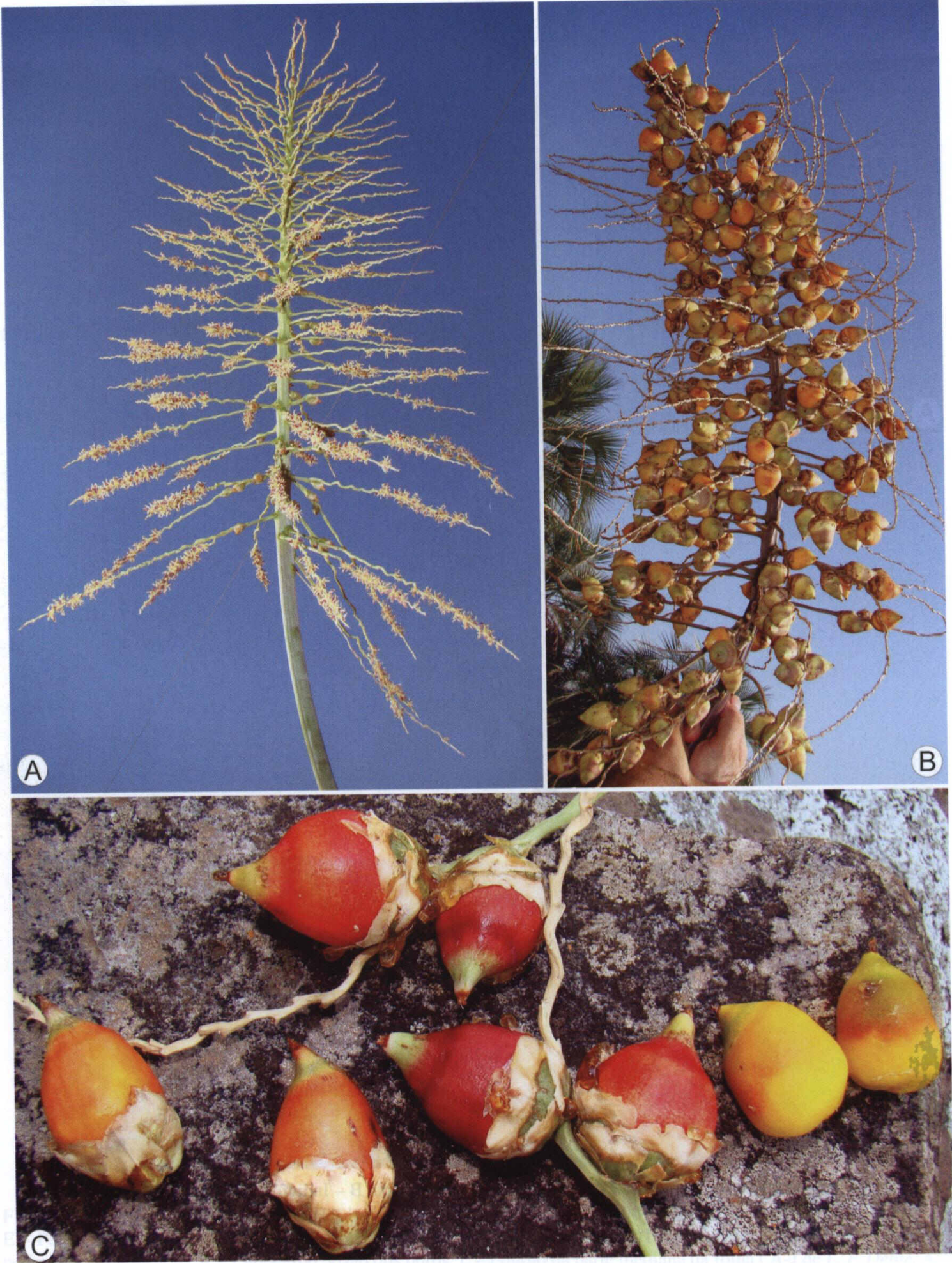

FIGURA 4 - Butia quaraimana. A - Inflorescência. B - Infrutescência (cacho). C - Frutos maduros. 


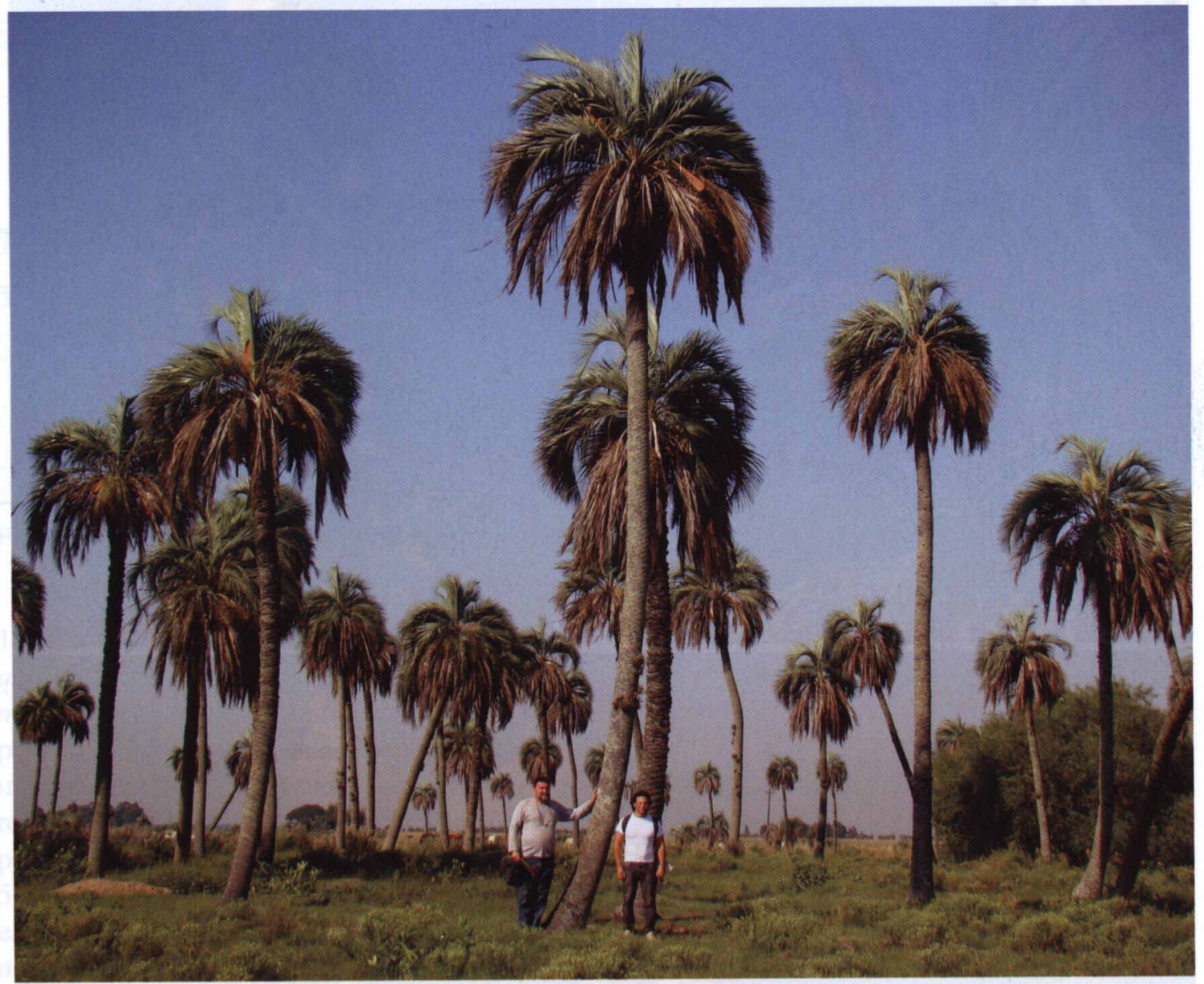

FIGURA 5 - Vista panorâmica de um fragmento do palmar de Butia yatay de San Roque (Corrientes, Argentina). 

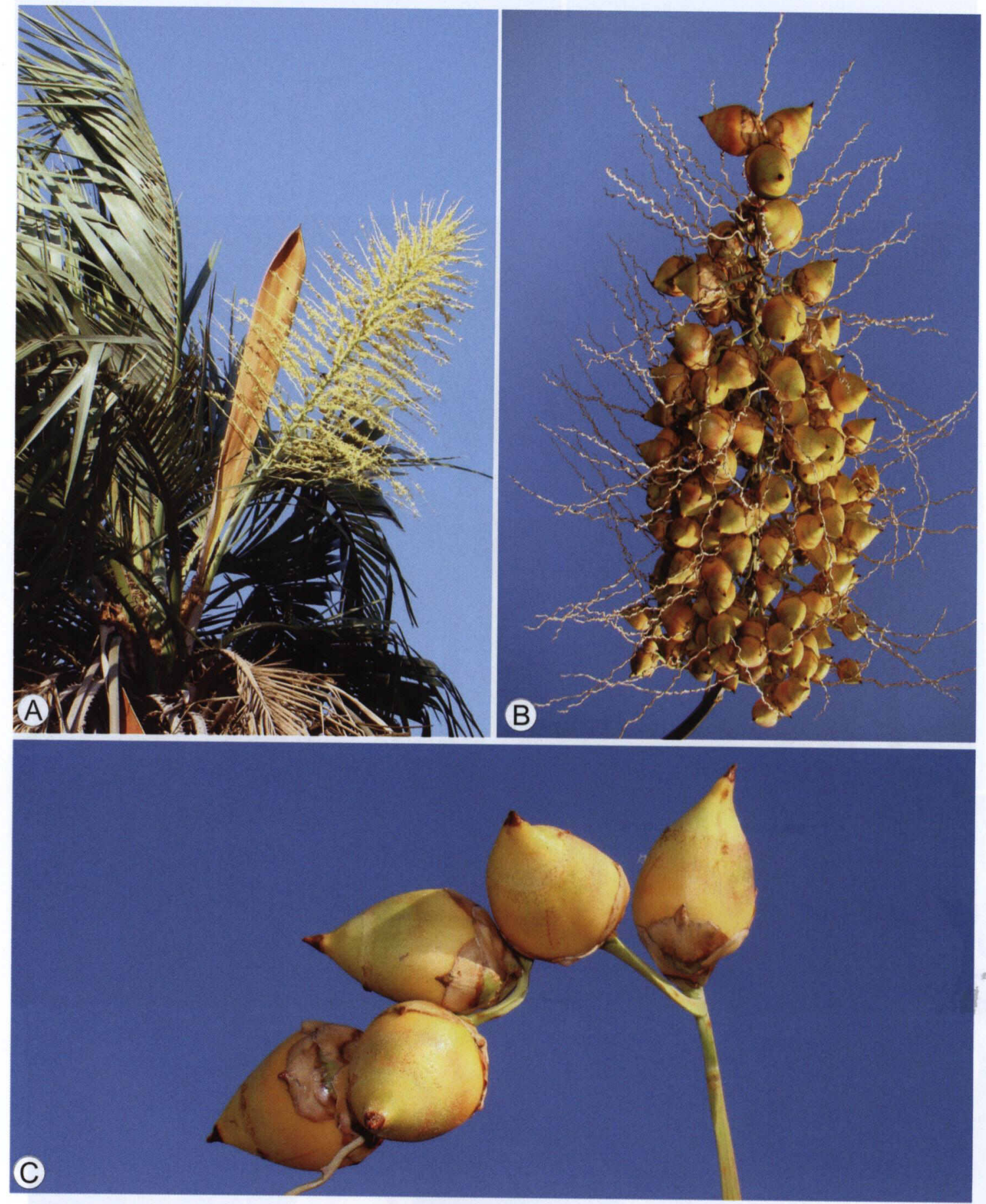

FIGURA 6 - Butia yatay. A - Inflorescência, bráctea peduncular e folhas. B - Infrutescência (cacho). C - Frutos, em detalhe. 


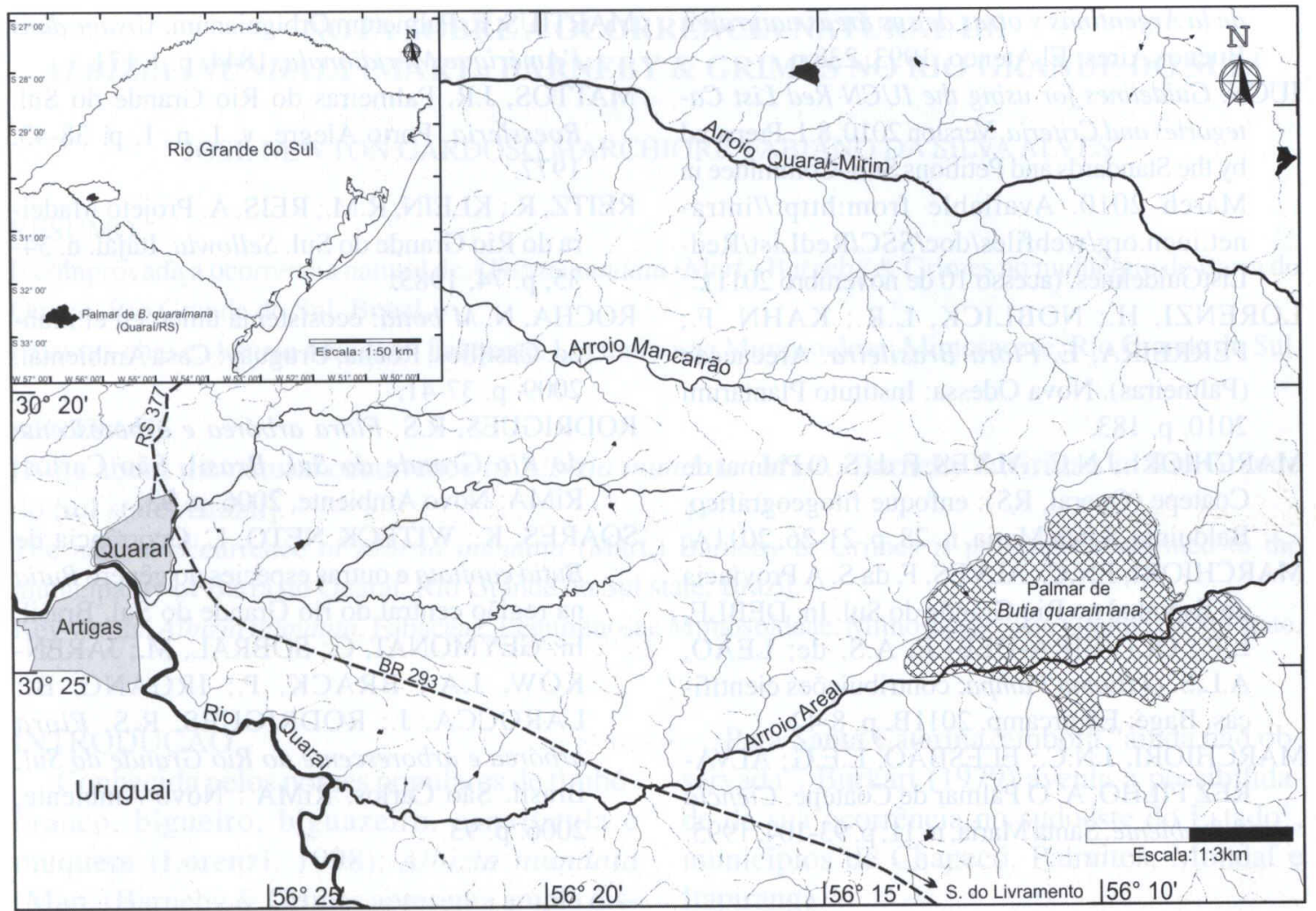

FIGURA 7 - Mapa de localização do Palmar de Butia quaraimana.

$12 \mathrm{~mm}$ (vs. 28-35 mm x 16-23 mm). Butia quaraimana ainda demonstra afinidade $\operatorname{com} B$. missionera Deble \& Marchiori, da qual difere pelas folhas ereto-arqueadas ou arqueadas ( $v s$. inicialmente ereto-arqueadas, posteriormente recurvadas, ocultando a metade distal do estipe), pelo estipe delgado (30-40 $\mathrm{cm}$ de diâmetro $v s$. $50-60 \mathrm{~cm}$ de diâmetro), cilíndrico em quase toda extensão ( $v s$. engrossado na base), pelo menor número de folhas contemporâneas (12-16 vs. 2540), assim como pela forma ovado-turbinada do fruto ( $v s$. largamente ovóide).

Conservação: Butia quaraimana é conhecida apenas para a localidade típica, em área de aproximadamente $42 \mathrm{~km}^{2}$ (Figura 7). A população está sofrendo declínio gradativo, devido à falta de regeneração. De acordo com os critérios da IUCN (2010), Butia quaraimana Deble \& Marchiori é considerada criticamente ameaçada: CR B1 a, b (I, II, III, IV, V).
Paratypi: BRAZIL. Rio Grande do Sul, Quaraí, Palmar do Coatepe, "no campo, entre rochas, estipe $5 \mathrm{~m}$, bráctea peduncular glabra, frutos apiculados" 9-III-2007, L. P. Deble, A. S. Oliveira-Deble \& J. N. C. Marchiori 7456 (CTES).

\section{REFERÊNCIAS BIBLIOGRÁFICAS}

BECCARI, O. Il genere Cocos Linn. e le palme affini. Agricoltura Coloniale, Florença, Itália, v. 10, p. 489-524, 1916.

DEBLE, L.P.; MARCHIORI, J.N.C.; ALVES, F. da S.; OLIVEIRA-DEBLE, A.S. de. Survey on Butia (Becc.) Becc. (Arecaceae) from Rio Grande do Sul state (Brazil). Balduinia, Santa Maria, n. 30, p. 21, 2011.

D'ORBIGNY, A.D. Viaje por América meridional. Buenos Aires: Emecé, 1998. v. 1. 524 p.

ERIZE, F.; CANEVARI, M.; CANEVARI, P.; COSTA, G.; RUMBOLL, M. Los parques nacionales 
de la Argentinas y otras de sus áreas naturales. Buenos Aires: El Ateneo, 1993. 238 p.

IUCN. Guidelines for using the IUCN Red List Categories and Criteria. Version 2010. 8.1. Prepared by the Standards and Petitions Sub-Committee in March 2010. Available from:http://intranet.iucn.org/webfiles/doc/SSC/RedList/RedListGuidelines. (acesso 10 de novembro 2011).

LORENZI, H.; NOBLICK, L.R.; KAHN, F.; FERREIRA, E. Flora Brasileira. Arecaceae (Palmeiras). Nova Odessa: Instituto Plantarum 2010. p. 183.

MARCHIORI, J.N.C.; ALVES, F. da S. O Palmar de Coatepe (Quaraí, RS): enfoque fitogeográfico. Balduinia, Santa Maria, n. 28, p. 21-26, 2011 A.

MARCHIORI, J.N.C.; ALVES, F. da S. A Província do Espinhal no Rio Grande do Sul. In: DEBLE, L.P.; OLIVEIRA-DEBLE, A.S. de; LEÃO, A.L.S. O Bioma Pampa: contribuições científicas. Bagé: Ediurcamp, 2011B. p. 8-42.

MARCHIORI, J.N.C.; ELESBÃO, L.E.G.; ALVAREZ FILHO, A. O Palmar de Coatepe. Ciência \& Ambiente, Santa Maria, n. 11, p. 93-104, 1995.
MARTIUS, F. Palmetum Orbignianum. Voyage dans l'Amérique Méridionale, 1844. p. 1-171.

MATTOS, J.R. Palmeiras do Rio Grande do Sul. Roessleria, Porto Alegre, v. 1, n. 1, p. 38-43, 1977.

REITZ, R.; KLEIN, R.M.; REIS, A. Projeto Madeira do Rio Grande do Sul. Sellowia, Itajaí, n. 3435, p. 74, 1983.

ROCHA, N. M'botiá: ecosistema único en el mundo. Castillos, Rocha, Uruguay: Casa Ambiental, 2009. p. 37-41.

RODRIGUES, R.S. Flora arbórea e arborescente do Rio Grande do Sul, Brasil. São Carlos: RiMA: Novo Ambiente, 2006. p. 93.

SOARES, K.; WITECK NETO, L. Ocorrência de Butia capitata e outras espécies do gênero Butia na região central do rio Grande do Sul, Brasil. In: GEYMONAT, G.; SOBRAL, M.; JARENKOW, J.A.; BRACK, P.; IRGANG, B.; LAROCCA, J.; RODRIGUES, R.S. Flora arbórea e arborescente do Rio Grande do Sul, Brasil. São Carlos: RiMA : Novo Ambiente, 2006. p. 93. 